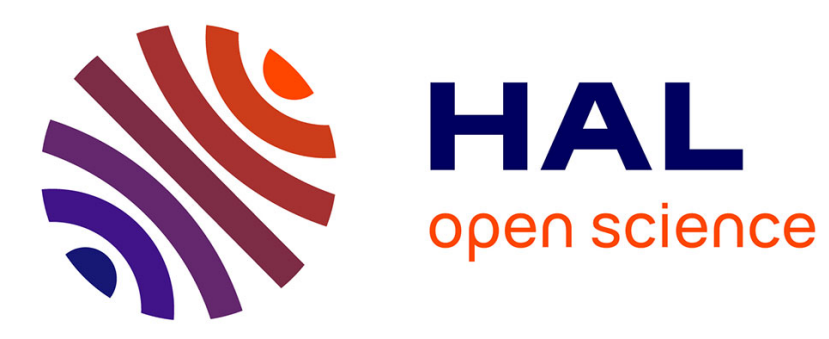

\title{
Effects of plant functional traits on soil stability: intraspecific variability matters
}

Hamada Ali, Björn Reineking, Tamara Münkemüller

\section{To cite this version:}

Hamada Ali, Björn Reineking, Tamara Münkemüller. Effects of plant functional traits on soil stability: intraspecific variability matters. Plant and Soil, 2017, 411 (1-2), pp.359-375. 10.1007/s11104-0163036-5 . hal-02324182

\section{HAL Id: hal-02324182 \\ https://hal.science/hal-02324182}

Submitted on 25 May 2020

HAL is a multi-disciplinary open access archive for the deposit and dissemination of scientific research documents, whether they are published or not. The documents may come from teaching and research institutions in France or abroad, or from public or private research centers.
L'archive ouverte pluridisciplinaire HAL, est destinée au dépôt et à la diffusion de documents scientifiques de niveau recherche, publiés ou non, émanant des établissements d'enseignement et de recherche français ou étrangers, des laboratoires publics ou privés. 
2

3

Hamada E. Ali ${ }^{1,2}$, Björn Reineking ${ }^{1,3}$, and Tamara Münkemüller ${ }^{4,5}$

4

$5 \quad 1$ Biogeographical modelling, Bayreuth Center for Ecology and Environmental Research BayCEER, University

6 of Bayreuth, Universitaetsstr. 30, D-95440 Bayreuth, Germany.

$7 \quad 2$ Botany Department, Faculty of Science, Suez Canal University, 41522 Ismailia, Egypt.

83 Unité Écosystèmes Montagnards, Irstea - Centre de Grenoble, 2, rue de la Papeterie-BP 76, F-38402 St-

9 Martin-d'Hères Cedex, France.

104 Univ. Grenoble Alpes, Laboratoire d'Écologie Alpine (LECA), F-38000 Grenoble, France.

115 CNRS, Laboratoire d'Écologie Alpine (LECA), F-38000 Grenoble, France

12

$13 *$ Correspondence author:

14 Hamada E. Ali,

15 Biogeographical modelling, University of Bayreuth,

16 Universitaetsstr. 30, D-95440 Bayreuth, Germany

17 e-mail: hamada.ali@uni-bayreuth.de

18 Phone: $+49(0) 921552064$ 


\section{Abstract}

Background and Aims: Soil stability is a key ecosystem function provided by agricultural landscapes. A multitude of influential factors such as soil texture and plant community structure have been suggested, but few studies compare the relative importance of these factors for soil stability in the field. In addition, studies on effects of plant traits on soil stability have ignored intraspecific trait variability (ITV) despite growing evidence of its importance for ecosystem functioning.

Methods: Using path model analysis, we quantified the effect of plant functional traits (PFTs), abiotic soil characteristics (soil texture) and vegetation characteristics on three soil stability measures in 30 field margins of an agriculture landscape of Korea, comparing models with and without ITV.

Results: Variance in soil stability was explained to varying degrees (from $81 \%$ for soil aggregate stability to $35 \%$ for soil shear vane strength). The three soil stability measures were mainly affected directly by root density, while PFTs and soil texture exerted indirect effects through root density and vegetation parameters, respectively. Including ITV improved model explained variance and goodness-of-fit in all cases.

Conclusion: The current study demonstrates that considering ITV is essential for uncovering the substantial effect of plant functional community composition on a key ecosystem function, soil stability.

Keywords: agricultural landscapes, community-weighted mean traits, intraspecific trait variability, plant functional traits, response and effect traits, root density, soil stability. 
Understanding the processes that drive the degradation of ecosystem functions in agricultural landscapes is of pivotal interest given ongoing land-use and climate change (Cardinale et al. 2012). Although ecosystem functions are strongly affected by the direct impact of these abiotic drivers, it is also modulated by biotic factors (Loreau et al. 2001). A number of studies has aimed at identifying the most important biotic drivers and it has been suggested that often the functional composition of ecological communities is more important for the maintenance of ecosystem functioning than species richness per se (Diaz et al. 2006; Laughlin 2014).

Different metrics of functional community composition can be measured in different ways. Recent studies suggest that community weighted means of functional traits (CWM), obtained by taking the mean trait value of a species weighted by its relative abundance in the focal community and then summed over all species (Garnier et al. 2004), relate better to ecosystem functioning than functional diversity metrics (Fortunel et al. 2009; Laughlin 2011). Even though commonly applied (Díaz et al. 2007; Garnier et al. 2004) this metric has the problem that it ignores intraspecific trait variability. However, intraspecific variability can be large and is often not random but a result of adaptation or phenotypic plasticity of traits either along environmental gradients (Sandquist and Ehleringer 1997), or a response to biotic interactions (Albert et al. 2011; Gross et al. 2009). Intraspecific trait variability, thus, can strongly influence the estimates of community trait composition (Jung et al. 2014). Consequently, it has been strongly advocated to account for intraspecific variability when calculating CWMs (Albert et al. 2010).

Here, we suggest studying community weighted means accounting for intraspecific trait variability, in order to better understand how different abiotic variables, vegetation characteristics and plant functional traits interact to influence an important ecosystem function: soil stability. Soil stability refers to the ecosystem function of resistance to disintegration when disturbed. Soil stability is critical for infiltration, root growth, and resistance to water and wind erosion (Bronick and Lal 2005; Gyssels et al. 2005) and thus is a crucial soil property affecting soil sustainability and crop production (Letey 1985). Soil stability can be measured in the field by several methods. The most common are: (1) Soil aggregate stability, which reflects how the soil aggregates react to precipitation, as the unstable aggregates tend to produce a slaked soil layer when it gets wet, which causes limitation in the infiltration rate, increasing the surface runoff and limiting the plant growth (Tisdall and Oades 1982). (2) Soil penetration resistance, a composite soil property that is 
governed by more basic properties, including soil cohesion, soil compressibility and soil/metal friction (Dexter et al. 2007). Penetration resistance correlates with several other important variables, such as root elongation rate (Taylor and Ratliff 1969). (3) Soil shear vane strength, which measures the soil cohesiveness and resistance to shearing forces exerted by gravity, moving fluids and mechanical loads (Morgan 2009). It reflects how the soil-root matrix produces a type of reinforced earth, which is much stronger than the soil or the roots separately and how this matrix can resist the environmental factors and human activities (Simon and Collison 2001).

There are many factors that control soil stability via direct and indirect pathways. Particularly important are abiotic soil characteristics such as soil texture and clay content (Chenu et al. 2011; Denef and Six 2005), biotic vegetation characteristics such as species richness, vegetation cover and plant diversity (Pérès et al. 2013; Pohl et al. 2009), and biotic functional characteristics such as plant roots, soil fauna, and microorganisms (Gyssels et al. 2005). In the following, we will shortly review the available literature on the interdependencies of these different factors and will summarize them in a conceptual path model reflecting a hypothesis on how abiotic and biotic factors interact and affect soil stability directly or indirectly (Fig. 1): Abiotic soil characteristics (e.g. soil texture with clay and silt percentages) influence soil stability directly. For example, fine soil particles (clay and silt) tend to increase, while coarse particles (sand and gravel) decrease soil stability (Nearing et al. 1991; Tisdall and Oades 1982). They also influence vegetation characteristics (e.g. vegetation cover, species richness and root density) and functional characteristics of plant communities, i.e. plant functional traits (PFTs) such as root/shoot ratio, root length and root horizontal width (Lane et al. 1998). Biotic vegetation characteristics also directly influence soil stability: Both above ground vegetation characteristics such as higher species richness, plant cover, and species diversity (Pérès et al. 2013; Pohl et al. 2012), as well as below ground vegetation characteristics, such as higher root length, root density, and root length density (Hu et al. 2013; Pohl et al. 2009) increase soil stability. The effect of vegetation characteristics on soil stability is due to multiple processes. First, plant roots forming a dense root network bind soil particles via root excretions (Gyssels et al. 2005; Traore et al. 2000). Secondly, a dense above ground vegetation protects the soil surface from wind and rain drops (Gray and Sortir 1996). Thirdly, a dense vegetation and root network enhances infiltration rates and reduces runoff (Tisdall and Oades 1982). Plant cover and species diversity impact not only soil stability but also species assembly in communities and thus the functional composition of communities (Petchey and Gaston 2002). In return, it has been shown that vegetation characteristics and 
root density depend strongly on the functional composition of communities (Reich et al.

109 2012). Finally, as argued before, species functional traits do not only respond to local abiotic

110 and biotic characteristics but they also play an important role in ecosystem functions. For soil

111 stability it has been shown that root length, root diameter and root horizontal width are

112 important determinants (Gyssels et al. 2005; Pohl et al. 2012).

113 The aim of this paper is to integrate vegetation characteristics and functional traits into a

114 model of abiotic soil characteristic effects on soil stability, towards an improved

115 understanding of ecosystem functioning. For this purpose we measure soil stability via soil

116 aggregate stability, soil penetration resistance and soil shear vane strength. First, we test how

117 well our conceptual model (outlined above and visualized in Fig. 1) fits data from field

118 margins in an agriculture landscape in Korea and how important intraspecific variability is for

119 this fit. Second, we investigate the importance of PFTs in comparison to the influence of

120 abiotic soil characteristics and biotic vegetation characteristics for soil stability. Finally, we

121 ask whether the identified functional effect traits are at the same time important functional

122 response traits. In other words, are the traits that determine the effect on ecosystem

123 functioning the same as those that determine the response of organisms to abiotic conditions

124 (Lavorel and Garnier 2002)? 
Study site and experimental design:

127 The study was conducted in the Haean-myun catchment in South Korea, which is located in the watershed of Soyang Lake close to the Demilitarized Zone (DMZ; $128^{\circ} 05^{\prime}$ to $128^{\circ} 11^{\prime}$ E, $38^{\circ} 13^{\prime}$ to $38^{\circ} 20^{\prime}$ N; Fig. 2). Elevation in the study site varies from 500 to $750 \mathrm{~m}$ a.s.1. The mean annual air temperature is $10.5{ }^{\circ} \mathrm{C}$, mean monthly temperature varies between $-10{ }^{\circ} \mathrm{C}$ in January and $27{ }^{\circ} \mathrm{C}$ in August (1999 - 2012). The average precipitation is 1,500 mm, with 70\% of the rain falling during the summer monsoon from June to August (Berger et al. 2013). The area is subjected to very heavy rains during the monsoon season, which causes severe damages to the soil, and thus soil stability is a very important ecosystem function.

Over the whole catchment, 30 plots of $1 \mathrm{~m}^{2}$ were randomly chosen. In each plot, we estimated (1) vegetation characteristics, (2) plant functional traits of in total 10 selected species, (3) soil characteristics (excluding soil stability) and (4) measures of soil stability.

In each plot, we estimated three different variables describing the vegetation characteristics: vegetation cover (i.e. the percentage of ground covered by vegetation), species richness (i.e. the number of observed species) and root density (estimated as percentage using a $30 \mathrm{~cm} \times 30$ cm metallic frame placed on the soil profile, following (Eckelmann 2006).

(2) Plant functional trait measurement and analyses

We measured above- and belowground plant functional traits (PFTs) for 15 individuals of the 10 most representative species in the study site (Table 1). The 10 most representative species were chosen based on their abundance in an earlier intensive botanical survey we conducted at the study site. To account for the community-level intraspecific variability of traits, we collected individuals in the plots, with a maximum of 3 individuals per species per plot. Depending on the distribution of the species, between 0 and 3 individuals of each species were collected in each plot. Following this sampling design we finally had trait information for an average of $51 \%$ of the vegetation cover in the plots $(\min =30 \%$ and $\max =75 \%$ ). 
We collected the above- and belowground biomass of the 150 studied individuals. We measured plant height (Cornelissen et al. 2003) and leaf size (Cornelissen et al. 2003) for the aboveground compartment of each individual. We washed, dried, weighted and scanned the roots of each individual in order to measure root horizontal width (Cornelissen et al. 2003; Lobet et al. 2011), root length and diameter (Lobet et al. 2011), root dry mass (Cornelissen et al. 2003), specific root length (SRL), which is the root length divided by the root dry weight (Cornelissen et al. 2003), and root/shoot ratio (Monk 1966).

We then up-scaled functional properties to the community level using community weighted means for each of the PFTs (Garnier et al. 2007; Lavorel et al. 2008; Violle et al. 2007). In order to investigate the importance of intraspecific trait variability we used two different CWM estimates, one that neglects intraspecific variability $\left(\mathrm{CWM}_{\text {species }}\right)$ and one that integrates it at the level of each local community $\left(\mathrm{CWM}_{\mathrm{j}}\right)$. To account for intraspecific variability, we calculated the $\mathrm{CWM}_{\mathrm{j}}$ within each plot based on the locally observed mean species trait value and the species' relative cover:

8

$$
\mathrm{CWM}_{\mathrm{j}}=\sum_{\mathrm{i}=1}^{\mathrm{n}} \mathrm{p}_{\mathrm{ij}} * \text { trait }_{\mathrm{ij}}
$$

Where $p_{i j}$ is the relative cover $\%$ of species (i) in the community plot ( $\mathrm{j}$ ) and trait $\mathrm{i}_{\mathrm{ij}}$ is the mean trait value of species (i) in the community plot (j). To calculate $\mathrm{CWM}_{\text {species }}$ we used the overall species mean trait value instead of the locally observed mean species trait value.

(3) Soil characteristic measurements and analyses (excluding stability):

In each plot, we estimated five different soil variables: Bulk density, water content, wettability, clay \% (i.e. percentage of clay), and silt \% (i.e. percentage of silt). We randomly sampled $30 \mathrm{~cm}$ deep soil profiles (from 0 to $30 \mathrm{~cm}$ ) at each plot. For the bulk density, we took three samples from the soil profile using soil rings with $2.8 \mathrm{~cm}$ diameter and $1 \mathrm{~cm}$ height. Soil rings were weighted, oven-dried for 24 hours at $105^{\circ} \mathrm{C}$ and finally weighed again (Avnimelech et al. 2001). Bulk density was calculated using the following equation:

$$
\text { Bulk density }\left(\mathrm{g} / \mathrm{cm}^{3}\right)=\text { dry sample weight } / \text { total sample volume }
$$


The soil water content was calculated as the difference between the ring weight before and after drying.

Soil wettability was assessed via the "water drop penetration time", (WDPT) (Letey 1969). Droplets of distilled water were placed onto the surface of the soil sample and the time for their complete infiltration was recorded. Measurements were replicated 10 times for each sample, and then the mean value was used for our analysis.

Soil texture was expressed as clay $\%$ and silt $\%$, following the standard sieve-pipette method procedures as described by Gee and Bauder (1986); soil samples were first dispersed into individual primary particles using hydrogen peroxide $\left(\mathrm{H}_{2} \mathrm{O}_{2}\right)$ and sodium hexametaphosphate $4 \%$, then the soil slurry was sieved through $0.63 \mathrm{~mm}, 0.2 \mathrm{~mm}$ and $0.063 \mathrm{~mm}$ sieves to separate coarse, medium and fine sand fractions. The remaining suspension, containing coarse, medium and fine silt and clay, was then transferred to a 1 liter cylinder and after stirring a sample was taken using a $50 \mathrm{ml}$ pipet at different time intervals depending on the temperature, to sample the fine, medium and coarse silt and clay. After drying and weighting the samples, $\%$ pipetted fraction was calculated as:

$\%$ pipetted fraction $=($ weight of the oven dry fraction $/$ weight of the original sample $) \times 100$

In addition, we used the soil profiles to estimate root density (a variable describing vegetation characteristics, see above).

\section{(4) Soil stability measurements}

The plot specific soil cores were also used to estimate variables of soil stability. We considered three different and commonly used variables: soil aggregate stability, penetration resistance and soil shear vane strength. We used the modified wet sieving method by (Haynes 1993) to measure soil aggregate stability, based on one surface soil sample per plot. In this method $100 \mathrm{~g}$ of the air-dried $24 \mathrm{~mm}$ soil aggregates were transferred to the uppermost of a set of five sieves with apertures ranging from 0.05 to $2 \mathrm{~mm}$. Then the sieves' set were transferred to a water-path were the oscillation rate was 2.5 cycles per minute and the amplitude of the sieving action was $3.5 \mathrm{~cm}$ for $15 \mathrm{~min}$. Then the sieves were oven dried at $105^{\circ} \mathrm{C}$ for 24 hours and the remaining aggregates at each sieve were weighted and the mean weight diameter (MWD) was calculated as follows:

$$
\operatorname{MWD}=\sum w_{i}^{*} x_{i}
$$


218 Where $i$ corresponds to each fraction collected, $w_{i}$ is the dry weight of the fraction collected

219 relative to the total soil used and $x_{i}$ is the mean diameter of the fraction collected.

220

221 In each of the 30 plots, we measured soil penetration resistance $\left(\mathrm{kg} / \mathrm{cm}^{2}\right)$ using a EW-9903900 pocket penetrometer (Cole-Parmer Cole-Parmer Instrument Company, Vernon Hills, IL., USA). Measurements of penetration resistance were replicated three times for each plot and the average value of them was included in the models.

For measuring soil shear vane strength $(\mathrm{kPa})$, we used a shear vane with a height of $80 \mathrm{~mm}$ and a diameter of $40 \mathrm{~mm}$ with three measures per plot. Shear strength was calculated using the following equation:

$$
\tau_{\mathrm{f}}=\frac{\mathrm{T}}{2 \pi \mathrm{r}_{\mathrm{v}}^{2}\left(\left(\frac{2}{3}\right) \mathrm{r}_{\mathrm{v}}+\mathrm{h}\right)}
$$

Where $\tau_{\mathrm{f}}$ is the shear strength of the soil, $\mathrm{T}$ is the maximum torque at failure, $\mathrm{h}$ is the height of the vane and $r_{v}$ is the diameter of the vane (Richards 1988). Three replicate measurements were made at each plot and the average value was used in the models.

\section{Statistical Analyses:}

The aim of our study was to evaluate our conceptual path model on the influence of vegetation characteristics, soil characteristics and PFTs on soil stability that we developed in the introduction (Fig. 1) with our data. Towards this aim path analyses were performed independently for the three measures of soil stability.

In a first step, owing to the demanding field protocol of measuring intraspecific trait variability, which resulted in a limited sample size, we reduced the number of variables measured to describe vegetation characteristics, soil characteristics and PFTs. As suggested by Wilson and Nussey (2010), variable selection was based on a redundancy analysis (RDA), which allowed us to choose those variables and traits that showed a significant relation to soil stability. We performed this independent pre-variable selection in order to obtain a common set of variables for all three soil stability measures and thus for all three independent path analyses.

In a second step, we fitted the conceptual path model with all remaining variables based on a Partial Least Squares Path Modeling (PLS-PM) approach. Model evaluation of PLS-PMs was based on the $R^{2}$ coefficient for the soil stability measure and the overall model goodness-of-fit 
249 (GoF) index. All statistical analyses were done using R, version 3.1.0 (R Development Core

250 Team 2013), with package PLSPM (Sanchez et al. 2013) for the path analysis, the RDA was 251 done using R package vegan (Oksanen et al. 2013). 
253

254

255

256

257

258

259

260

261

262

263

264

265

266

267

268

269

270

271

272

273

274

275

276

277

278

279

280

281

282

We found large intraspecific trait variability within the measured traits (Fig. S1). Species mean values ranged from 0.06 to 0.47 for root/shoot ratio (Fig. S1a), from 13.00 to $28.55 \mathrm{~cm}$ for root length (Fig. S1b), and from 3.44 to $18.25 \mathrm{~cm}$ for root horizontal width (Fig. S1c).

According to the RDA (Table 2), the vegetation variables that best describe soil stability were "vegetation cover percentage, species richness and root density". For the soil characteristics, the soil texture variables "silt and clay percentages" were most important and for the PFTs "root/shoot ratio, root horizontal width and root length". We kept these variables in the following PLS-PM approaches, which we describe independently for the three variables of soil stability.

We fitted of our conceptual path model to data either by ignoring intraspecific trait variability (using $\mathrm{CWM}_{\text {species }}$ as metrics for the PFTs) or by accounting for it at the scale of the communities (using $\mathrm{CWM}_{\mathrm{j}}$ as metrics for the PFTs).

Ignoring intraspecific trait variability resulted in lower quality performance of our path models; the explained variance was $79 \%, 49 \%$ and $35 \%$ for aggregate stability, penetration resistance and shear vane strength, respectively, and goodness-of-fit was $0.45,0.41$ and 0.38 (see Table S1; Figs. S2, S3). Direct and indirect effects of PFTs on soil stability were negligible (with standardized path coefficients, spc, 0.16, 0.09 and -.03 for the three stability measures). We therefore decided only to present the results of the models accounting for intraspecific variability in more detail.

Soil aggregate stability (models accounting for intraspecific variability):

Our conceptual path model explained $81 \%$ of the variance of soil aggregate stability with a goodness-of-fit index of 0.58 (Fig. 3a). Root density and vegetation cover were the most important factors that directly affected soil aggregate stability (with standardized path coefficients, spc, of 0.55 and 0.26 respectively), while the indirect effects of soil texture and the PFTs on soil aggregate stability resulted in the highest total effects (with spc equal to 0.66 and 0.50 respectively, Table S2; Fig. 4a). The high total effects of soil texture resulted from the strong direct effects of soil texture on PFTs and vegetation cover (and partly on species richness, which had a moderate effect on soil aggregate stability), while the high total effects of PFTs resulted from their strong link to root density which itself had a strong influence on 
soil aggregate stability. Moreover, PFTs were significantly affected by soil texture and species richness.

The crossloading effects that allow differentiating between the different PFTs (i.e. root/shoot ratio, root length and root horizontal width) (Fig. 5a) showed that the root/shoot ratio has the strongest effect on soil aggregated stability $(\mathrm{spc}=0.72)$ followed by root length $(\mathrm{spc}=0.54)$ and root horizontal width $(\mathrm{spc}=0.52$, Fig. $5 \mathrm{a})$. The silt and clay percentages had similar effects on soil aggregated stability (with spc equal to 0.65 and 0.60 respectively).

\section{Penetration resistance (models accounting for intraspecific variability):}

For the soil penetration resistance, our conceptual path model explained $50 \%$ of the variance with a goodness-of-fit index of 0.54 (Fig. 3b). Root density and soil texture were the most important factors that directly affected soil aggregate stability (with standardized path coefficients, spc, of 0.58 and 0.44 respectively), while PFTs showed the strongest indirect effect on penetration resistance (with spc equal to 0.30, Table S2; Fig. 4b). These strong indirect effects of PFTs resulted from their strong link to root density which itself had a strong influence on soil penetration resistance. As in the soil aggregate stability model, PFTs were significantly affected by soil texture and species richness.

The crossloading effects showed a slightly different order of relative importance of the different PFTs (Fig. 5b) than in the soil aggregate stability model: For soil penetration resistance, root length (and not root/shoot ration) was most important $(\mathrm{spc}=0.51)$ followed by root/shoot ration $(\mathrm{spc}=0.48)$ and root horizontal width $(\mathrm{spc}=0.20$, Fig. $5 \mathrm{~b})$. The silt and clay percentages showed the same trends as in the soil aggregate stability model $(\mathrm{spc}=0.54$ and 0.53 respectively).

Soil shear vane strength (models accounting for intraspecific variability):

In the soil shear vane strength model, $35 \%$ of the variance was explained, with a goodness-offit index of 0.52 (Fig. 3c). Root density was the most important factor that directly affected soil aggregate stability $(\mathrm{spc}=0.54)$, while the indirect effects of soil texture and PFTs on shear vane strength had the highest total indirect effects $(\mathrm{spc}=0.52$ and $\mathrm{spc}=0.22$, respectively, Table S2; Fig. 4c). Soil texture had a strong direct effect on PFTs and species richness. PFTs showed a strong relation to root density which itself had a strong influence on 
314 shear vane strength. As before, PFTs were significantly affected by soil texture and species 315 richness.

316 The crossloading effects were comparable to those in the penetration resistance path model

317 (Fig. 5c), as both the root/shoot ratio and root length were most important $(\mathrm{spc}=0.43$ and 3180.40 respectively), while the root horizontal was much less important $(\mathrm{spc}=0.10)$. As before, 319 silt and clay percentages were equally important ( $\mathrm{spc}=0.47$ and 0.40 respectively).

320 Overall, we found that ignoring intraspecific trait variability resulted in lower fit for our 321 conceptual model to the data. Accounting for intraspecific variability, the three components of 322 soil stability were either moderately (soil shear vane strength, soil penetration resistance) or 323 well (soil penetration resistance) explained by our conceptual path model. In all three 324 analyses, root density had the strongest direct effect on soil stability. Accounting in addition 325 for indirect effects, we could show that PFTs had a similarly strong influence, which was 326 mostly mediated by root density. The most important PFTs were root length and the 327 root/shoot ratio. PFTs themselves were strongly affected by species richness and soil texture. 


\section{Discussion:}

329 Our study is one of the few to investigate the combined influence of plant functional traits

330 (PFTs), vegetation characteristics and abiotic soil characteristics on ecosystem functioning in

331 the field. We built a conceptual path model to disentangle the different abiotic and biotic

332 drivers of soil stability as one of the important ecosystem functions impacting erosion control

333 and nutrient supply in agriculture landscapes. We confronted this model with data collected in

334 field margins in South Korea. Results highlight the important effect of the functional

335 composition of communities on soil stability. Notably, this effect could only be seen when

336 considering intraspecific variability in PFTs.

Explained variation in soil stability

339

Our conceptual model hypothesizes that soil stability is not only strongly influenced by abiotic variables (e.g. soil structure) and vegetation structure (e.g. cover, species richness) but also by the functional composition of plant communities. Overall, our data from South Korean field margins support this hypothesis.

When intraspecific trait variability was considered, the conceptual model explained moderate to large parts of the variation in the three considered measures of soil stability. Aggregated stability was best explained (81\%) followed by penetration (50\%) and shear strength $(35 \%)$. In comparison, goodness-of-fit values were not very high (0.52-0.58), a result that is due to the relative low sample size resulting from the considerable practical challenge posed by the indispensability of accounting for intraspecific variability in trait compositions.

The three measures of soil stability quantify different facets of soil stability: Aggregate stability has a strong influence on infiltration rate and surface runoff (Gyssels et al. 2005); penetration resistance strongly influences root elongation rates (Dexter et al. 2007), and is further related to retention, erosion, crusting and nutrient cycling (Bronick and Lal 2005; Chapman et al. 2012); finally, soil shear strength influences the resistance of the soil-root matrix to disturbances (Simon and Collison 2001), erosion (Morgan 1996), and crushing (Gyssels et al. 2005). While the amount of variation explained by our models differed across these three facets of soil stability, the models were largely congruent in the attribution of relative importance to soil texture, root density, and, notably, the role of intraspecific variability in PFTs, emphasizing the robustness of our results. 
360

361

362

363

364

365

366

367

368

369

370

371

372

373

374

375

376

377

378

379

One of our most striking results is that fitting the conceptual model with average trait data (i.e. ignoring intraspecific trait variability) led to poor model performance. Especially, the effect of functional plant community composition on the different components of soil stability was strongly underestimated when ignoring intraspecific variability. In addition we found that even though species significantly differ in their mean trait values, intraspecific trait variation is large and trait distributions of different species overlap (see supplementary material, Fig. $\mathrm{S} 1)$. Together these results imply that soil stability is significantly influenced by functional plasticity of plants.

The abiotic variable soil texture was the most important variable in our model. The fine particles of the soil texture (clay and silt) improve soil stability (Chenu et al. 2011; Nearing et al. 1991; Tisdall and Oades 1982). It has been currently suggested that this positive effect is rather due to the electrostatic bonds or physical forces (Arvidsson and Keller 2011; Denef and Six 2005), than due to organic cementing agents (Six et al. 2000). Functional community composition and root density had very strong impacts as well. Root/shoot ratio, root length and root horizontal width influenced all components of soil stability strongly and mostly via their impacts on root density. The effect of root/shoot ratio, root length or root horizontal width is mediated via root density due to its role in (1) microbial community compositions in the rhizosphere which in turn supports soil stability (Gyssels and Poesen 2003), (2) in reducing soil porosity (Graf and Frei 2013; Pérès et al. 2013; Pohl et al. 2009), and (3) binding soil particles together via root exudates and mucilage (Eisenhauer et al. 2010; Pojasok and Kay 1990; Traore et al. 2000).

Interestingly, the effect of PFTs on soil stability via root density is much more important than the effects of species richness and partly vegetation cover, a result that is in concordance with recent literature (Graf and Frei 2013; Pérès et al. 2013). Species richness did not directly affect soil stability at all but affected root density and PFTs. The impact of vegetation cover was overall small. Our results highlight, the importance of not only abiotic but also biotic variables for soil stability. The most important biotic variables are strongly related to ecosystem functioning.

To our knowledge, this is the first field study to demonstrate the key role of plant functional traits in soil stability, while accounting for intraspecific trait variability. Soil stability of field margins is of particular relevance for agricultural landscapes subjected to extreme heavy rains during the monsoon season, as it contributes to the control of soil erosion and nutrient 
cycling. Our results further corroborate the notion that ecosystem functions (e.g. soil stability) are related to the functional composition of the community rather than species diversity per se (Díaz and Cabido 2001).

\section{Effect vs. response traits}

In our analyses we first selected effect traits that related well to soil stability. The integration of these effect traits into our conceptual model allowed us then to evaluate if the same traits well described responses to abiotic conditions. Results showed a strong influence of soil texture on PFTs. Consequently we can conclude that root/shoot ratio, root length and root horizontal width, are at the same time important response and effect traits.

Our results suggest that understanding the response of plant communities to abiotic conditions benefits from accounting for plant phenotypic plasticity. High plant phenotypic plasticity in response and effect traits renders the challenge of managing field margins more difficult and simpler; more difficult, because management is difficult to optimize when targeting species based on their mean traits is not likely to work, and simpler, because management will be robust when several target species can provide the same required effect traits.

\section{Conclusion}

Our study demonstrates the important role of intraspecific trait variability not only in responses of plant communities to changing conditions but also in their effect on key ecosystem functions. Results corroborate for an important specific example (soil stability in agricultural landscapes) earlier findings suggesting that the functional trait composition of communities can be much more important for ecosystem functioning than vegetation cover or species richness. These findings have important implications for managing field margins in order to improve soil stability as communities should not only be enriched by species with favorable root traits but it should also be considered that species show important plasticity in their root traits. 
420 This work is part of the International Research Training Group "Complex TERRain and 421 ECOlogical Heterogeneity" (TERRECO) (GRK 1565/1) funded by the German Research 422 Foundation (DFG). We thank Sebastian Arnhold, Mareike Ließ, Marianne Ruidisch and Iris 423 Schmiedinger for supporting us in the field and the lab work, Bernd Huwe for his comments 424 and suggestions on our field protocol and soil analyses and John Tenhunen for his comments 425 and coordination of the TERRECO fieldwork. 
Albert CH, Grassein F, Schurr FM, Vieilledent G, Violle C (2011) When and how should intraspecific variability be considered in trait-based plant ecology? Perspectives in Plant Ecology, Evolution and Systematics 13: 217-225. doi: http://dx.doi.org/10.1016/j.ppees.2011.04.003.

Albert CH, Thuiller W, Yoccoz NG, Soudant A, Boucher F, Saccone P, Lavorel S (2010) Intraspecific functional variability: extent, structure and sources of variation. Journal of Ecology 98: 604613. doi: 10.1111/j.1365-2745.2010.01651.x.

Arvidsson J, Keller T (2011) Comparing penetrometer and shear vane measurements with measured and predicted mouldboard plough draught in a range of Swedish soils. Soil and Tillage Research 111: 219-223. doi: http://dx.doi.org/10.1016/j.still.2010.10.005.

Avnimelech Y, Ritvo G, Meijer LE, Kochba M (2001) Water content, organic carbon and dry bulk density in flooded sediments. Aquacultural Engineering 25: 25-33. doi: http://dx.doi.org/10.1016/S0144-8609(01)00068-1.

Berger S, Jang I, Seo J, Kang H, Gebauer G (2013) A record of N2O and CH4 emissions and underlying soil processes of Korean rice paddies as affected by different water management practices. Biogeochemistry 115: 317-332. doi: 10.1007/s10533-013-9837-1.

Bronick CJ, Lal R (2005) Soil structure and management: a review. Geoderma 124: 3-22. doi: http://dx.doi.org/10.1016/i.geoderma.2004.03.005.

Cardinale BJ, Duffy JE, Gonzalez A, Hooper DU, Perrings C, Venail P, Narwani A, Mace GM, Tilman D, Wardle DA, Kinzig AP, Daily GC, Loreau M, Grace JB, Larigauderie A, Srivastava DS, Naeem S (2012) Biodiversity loss and its impact on humanity. Nature 486: 59-67. doi: 10.1038/nature11148.

Chapman N, Miller AJ, Lindsey K, Whalley WR (2012) Roots, water, and nutrient acquisition: let's get physical. Trends in Plant Science 17: 701-710. doi: http://dx.doi.org/10.1016/j.tplants.2012.08.001.

Chenu C, Abiven S, Annabi M, Barray S, Bertrand M, Bureau F, Cosentino D, Darboux F, Duval O, Fourrié L, Francou C, Houot S, Jolivet C, Laval K, Le Bissonnais $Y$, Lemée L, Menasseri S, Pétraud JP, Verbèque $B$ (2011) Mise au point d'outils de prévision de l'évolution de la stabilité de la structure de sols sous l'effet de la gestion organique des sols. Etude Gest Sols: 161-174.

Cornelissen JHC, Lavorel S, Garnier E, Diaz S, Buchmann N, Gurvich DE, Reich PB, ter Steege H, Morgan HD, van der Heijden MGA, Pausas JG, Poorter H (2003) A handbook of protocols for standardised and easy measurement of plant functional traits worldwide. Aust J Bot 51: 335380. doi: 10.1071/bt02124.

Denef K, Six J (2005) Clay mineralogy determines the importance of biological versus abiotic processes for macroaggregate formation and stabilization. European Journal of Soil Science 56: 469-479. doi: 10.1111/j.1365-2389.2004.00682.x.

Dexter AR, Czyż EA, Gaţe OP (2007) A method for prediction of soil penetration resistance. Soil and Tillage Research 93: 412-419. doi: http://dx.doi.org/10.1016/i.still.2006.05.011.

Díaz S, Cabido M (2001) Vive la différence: plant functional diversity matters to ecosystem processes. Trends in Ecology \& Evolution 16: 646-655. doi: 10.1016/s0169-5347(01)02283-2.

Diaz S, Fargione J, Chapin FS, Tilman D (2006) Biodiversity loss threatens human well-being. PLoS Biology 4: 1300-1305. doi: 10.1371/journal.pbio.0040277.

Díaz S, Lavorel S, de Bello F, Quétier F, Grigulis K, Robson TM (2007) Incorporating plant functional diversity effects in ecosystem service assessments. Proceedings of the National Academy of Sciences 104: 20684-20689. doi: 10.1073/pnas.0704716104.

Eckelmann W (2006) Bodenkundliche Kartieranleitung. 5. Verbesserte und Erweiterte Auflage [“Pedological Mapping Guidelines. 5th Improved and Extended Edition"]. Schweizerbart'sche Verlagsbuchhandlung, Stuttgart.

Eisenhauer N, Bessler H, Engels C, Gleixner G, Habekost M, Milcu A, Partsch S, Sabais ACW, Scherber C, Steinbeiss S, Weigelt A, Weisser WW, Scheu S (2010) Plant diversity effects on soil 
microorganisms support the singular hypothesis. Ecology 91: 485-496. doi: 10.1890/082338.1.

Fortunel C, Garnier E, Joffre R, Kazakou E, Quested H, Grigulis K, Lavorel S, Ansquer P, Castro H, Cruz $P$, Doležal J, Eriksson O, Freitas $H$, Golodets $C$, Jouany $C$, Kigel J, Kleyer M, Lehsten V, Lepš J, Meier T, Pakeman R, Papadimitriou M, Papanastasis VP, Quétier F, Robson M, Sternberg M, Theau J-P, Thébault A, Zarovali M (2009) Leaf traits capture the effects of land use changes and climate on litter decomposability of grasslands across Europe. Ecology 90: 598-611. doi: 10.1890/08-0418.1.

Garnier E, Cortez J, Billès G, Navas M-L, Roumet C, Debussche M, Laurent G, Blanchard A, Aubry D, Bellmann A, Neill C, Toussaint J-P (2004) Plant functional markers capture ecosystem properties during secondary succession. Ecology 85: 2630-2637. doi: 10.1890/03-0799.

Garnier E, Lavorel S, Ansquer P, Castro H, Cruz P, Dolezal J, Eriksson O, Fortunel C, Freitas H, Golodets C, Grigulis K, Jouany C, Kazakou E, Kigel J, Kleyer M, Lehsten V, Lepš J, Meier T, Pakeman R, Papadimitriou M, Papanastasis VP, Quested H, Quétier F, Robson M, Roumet C, Rusch G, Skarpe C, Sternberg M, Theau J-P, Thébault A, Vile D, Zarovali MP (2007) Assessing the Effects of Land-use Change on Plant Traits, Communities and Ecosystem Functioning in Grasslands: A Standardized Methodology and Lessons from an Application to 11 European Sites. Annals of Botany 99: 967-985. doi: 10.1093/aob/mcl215.

Gee GW, Bauder JW (1986) Particle-size Analysis1. In: A Klute (ed) Methods of Soil Analysis: Part 1Physical and Mineralogical Methods. Soil Science Society of America, American Society of Agronomy.

Graf F, Frei M (2013) Soil aggregate stability related to soil density, root length, and mycorrhiza using site-specific Alnus incana and Melanogaster variegatus s.l. Ecological Engineering 57: 314323. doi: http://dx.doi.org/10.1016/j.ecoleng.2013.04.037.

Gray DH, Sortir RB (1996) Biotechnical and soil bioengineering slope stabilization: a practical guide for erosion control. John Wiley \& Sons.

Gross N, Kunstler G, Liancourt P, De Bello F, Suding KN, Lavorel S (2009) Linking individual response to biotic interactions with community structure: a trait-based framework. Functional Ecology 23: 1167-1178. doi: 10.1111/j.1365-2435.2009.01591.x.

Gyssels G, Poesen J (2003) The importance of plant root characteristics in controlling concentrated flow erosion rates. Earth Surface Processes and Landforms 28: 371-384. doi: 10.1002/esp.447.

Gyssels G, Poesen J, Bochet E, Li Y (2005) Impact of plant roots on the resistance of soils to erosion by water: a review. Progress in Physical Geography 29: 189-217.

Haynes RJ (1993) Effect of sample pretreatment on aggregate stability measured by wet sieving or turbidimetry on soils of different cropping history. Journal of Soil Science 44: 261-270. doi: 10.1111/j.1365-2389.1993.tb00450.x.

Hu L, Li P, Guo Q (2013) Positive Plant Diversity-Soil Stability Relationships are Mediated through Roots in the Songnen Grassland: Chronosequence Evidence. Not Bot Horti Agrobot Cluj-Na 41: 626-637.

Jung V, Albert CH, Violle C, Kunstler G, Loucougaray G, Spiegelberger T (2014) Intraspecific trait variability mediates the response of subalpine grassland communities to extreme drought events. Journal of Ecology 102: 45-53. doi: 10.1111/1365-2745.12177.

Lane DR, Coffin DP, Lauenroth WK (1998) Effects of soil texture and precipitation on above-ground net primary productivity and vegetation structure across the Central Grassland region of the United States. Journal of Vegetation Science 9: 239-250. doi: 10.2307/3237123.

Laughlin DC (2011) Nitrification is linked to dominant leaf traits rather than functional diversity. Journal of Ecology 99: 1091-1099. doi: 10.1111/j.1365-2745.2011.01856.x.

Laughlin DC (2014) The intrinsic dimensionality of plant traits and its relevance to community assembly. Journal of Ecology 102: 186-193. doi: 10.1111/1365-2745.12187.

Lavorel S, Garnier E (2002) Predicting changes in community composition and ecosystem functioning from plant traits: revisiting the Holy Grail. Functional Ecology 16: 545-556. doi: 10.1046/j.1365-2435.2002.00664.x. 
Lavorel S, Grigulis K, McIntyre S, Williams NSG, Garden D, Dorrough J, Berman S, Quétier F, Thébault A, Bonis A (2008) Assessing functional diversity in the field - methodology matters! Functional Ecology 22: 134-147. doi: 10.1111/j.1365-2435.2007.01339.x.

Letey J (1969) Measurement of contact angle, water drop penetration time, and critical surface tension. In: LF DeBano, J Letey (eds) Water Repellent Soils Proc Symp Water Repellent Soils. Univ. of California, University of California, Riverside.

Letey J (1985) Relationship between Soil Physical Properties and Crop Production. In: BA Stewart (ed) Advances in Soil Science. Springer New York.

Lobet G, Pagès L, Draye X (2011) A Novel Image-Analysis Toolbox Enabling Quantitative Analysis of Root System Architecture. Plant Physiology 157: 29-39. doi: 10.1104/pp.111.179895.

Loreau M, Naeem S, Inchausti P, Bengtsson J, Grime JP, Hector A, Hooper DU, Huston MA, Raffaelli D, Schmid B, Tilman D, Wardle DA (2001) Biodiversity and Ecosystem Functioning: Current Knowledge and Future Challenges. Science 294: 804-808. doi: 10.1126/science.1064088.

Monk C (1966) Ecological Importance of Root/Shoot Ratios. Bull Torrey Bot Club 93: 402-406. doi: $10.2307 / 2483412$.

Morgan RPC (2009) Soil erosion and conservation. John Wiley \& Sons.

Nearing MA, Bradford JM, Parker SC (1991) Soil detachment by shallow flow at low slopes. Soil Science Society of America Journal 55: 339-344.

Oksanen J, Guillaume Blanchet F, Kindt R, Legendre P, Minchin PR, O'Hara RB, Simpson GL, Solymos $P$, Henry M, Stevens H, Wagner H (2013) vegan: Community Ecology Package. R package version 2.0-9 edn.

Pérès G, Cluzeau D, Menasseri S, Soussana JF, Bessler H, Engels C, Habekost M, Gleixner G, Weigelt A, Weisser WW, Scheu S, Eisenhauer N (2013) Mechanisms linking plant community properties to soil aggregate stability in an experimental grassland plant diversity gradient. Plant and Soil 373: 285-299. doi: 10.1007/s11104-013-1791-0.

Petchey OL, Gaston KJ (2002) Functional diversity (FD), species richness and community composition. Ecology Letters 5: 402-411. doi: 10.1046/j.1461-0248.2002.00339.x.

Pohl M, Alig D, Körner C, Rixen C (2009) Higher plant diversity enhances soil stability in disturbed alpine ecosystems. Plant and Soil 324: 91-102. doi: 10.1007/s11104-009-9906-3.

Pohl M, Graf F, Buttler A, Rixen C (2012) The relationship between plant species richness and soil aggregate stability can depend on disturbance. Plant and Soil 355: 87-102. doi: 10.1007/s11104-011-1083-5.

Pojasok T, Kay BD (1990) Effect of root exudates from corn and bromegrass on soil structural stability. Canadian Journal of Soil Science 70: 351-362.

R Development Core Team (2013) R: A language and environment for statistical computing. R Foundation for Statistical Computing, Vienna, Austria.

Reich PB, Tilman D, Isbell F, Mueller K, Hobbie SE, Flynn DFB, Eisenhauer N (2012) Impacts of Biodiversity Loss Escalate Through Time as Redundancy Fades. Science 336: 589-592. doi: 10.1126/science.1217909.

Richards AF (1988) Vane shear strength testing in soils: Field and laboratory studies. Astm International.

Sanchez G, Trinchera L, Russolillo G (2013) plspm: Tools for Partial Least Squares Path Modeling (PLS$P M)$. R package version 0.4.1. edn.

Sandquist DR, Ehleringer JR (1997) Intraspecific variation of leaf pubescence and drought response in Encelia farinosa associated with contrasting desert environments. New Phytologist 135: 635644. doi: 10.1046/j.1469-8137.1997.00697.x.

Simon A, Collison A (2001) Scientific basis for streambank stabilization using riparian vegetation. Proceedings of the 7th Federal Interagency Sedimentation Conference.

Six J, Paustian K, Elliott E, Combrink C (2000) Soil structure and organic matter I. Distribution of aggregate-size classes and aggregate-associated carbon. Soil Science Society of America Journal 64: 681-689.

Taylor HM, Ratliff LF (1969) Root elongation rates of cotton and peanuts as a function of soil strength and soil water content. Soil Science 108: 113-\&. doi: 10.1097/00010694-196908000-00006. 
Tisdall JM, Oades JM (1982) Organic matter and water-stable aggregates in soils. Journal of Soil Science 33: 141-163. doi: 10.1111/j.1365-2389.1982.tb01755.x.

Traore O, Groleau-Renaud V, Plantureux S, Tubeileh A, Boeuf-Tremblay V (2000) Effect of root mucilage and modelled root exudates on soil structure. European Journal of Soil Science 51: 575-581. doi: 10.1111/j.1365-2389.2000.00348.x.

Violle C, Navas M-L, Vile D, Kazakou E, Fortunel C, Hummel I, Garnier E (2007) Let the concept of trait be functional! Oikos 116: 882-892. doi: 10.1111/j.0030-1299.2007.15559.x.

Wilson AJ, Nussey DH (2010) What is individual quality? An evolutionary perspective. Trends in Ecology \& Evolution 25: 207-214. doi: 10.1016/j.tree.2009.10.002. 
592 Table legends

593 Table 1. Above and below ground characteristics of the ten plant species studied in Haean-myun

594 catchment.

595

596 Table 2. RDA results between the three stability measures and the vegetation and soil parameters and 597 PFTs.

598 
Table 1.

600

\begin{tabular}{|c|c|c|c|c|c|c|c|c|c|c|}
\hline Name & Family & Duration & Life Form & Height (cm) & $\begin{array}{c}\text { Root / shoot } \\
\text { ratio }\end{array}$ & $\begin{array}{l}\text { Root } \\
\text { length } \\
\text { (cm) }\end{array}$ & $\begin{array}{c}\text { Root } \\
\text { diameter } \\
\text { (cm) }\end{array}$ & \begin{tabular}{|c|} 
Root \\
horizontal \\
width $(\mathrm{cm})$
\end{tabular} & $\begin{array}{l}\text { Specific } \\
\text { root } \\
\text { length }\end{array}$ & $\begin{array}{c}\text { Leaf size } \\
\quad\left(\mathrm{cm}^{2}\right)\end{array}$ \\
\hline Artemisia princeps Pamp. & Asteraceae & Perennial & Phanerophytes & $\begin{array}{c}88.03 \\
(11.80)\end{array}$ & $\begin{array}{c}0.24 \\
(0.07)\end{array}$ & $\begin{array}{l}20.55 \\
(5.41)\end{array}$ & $\begin{array}{c}0.24 \\
(0.03)\end{array}$ & $\begin{array}{r}18.25 \\
(1.98)\end{array}$ & $\begin{array}{l}14.03 \\
(7.70)\end{array}$ & $\begin{array}{c}75.28 \\
(28.72)\end{array}$ \\
\hline $\begin{array}{l}\text { Chelidonium majus var. asiaticum } \\
\text { (Hara) Ohwi }\end{array}$ & Papaveraceae & Annuals or biennials & Phanerophytes & $\begin{array}{r}83.07 \\
(15.97) \\
\end{array}$ & $\begin{array}{c}0.12 \\
(0.03)\end{array}$ & $\begin{array}{r}19.41 \\
(5.90) \\
\end{array}$ & $\begin{array}{c}0.23 \\
(0.05)\end{array}$ & $\begin{array}{r}10.77 \\
(4.96) \\
\end{array}$ & $\begin{array}{c}13.38 \\
(12.31)\end{array}$ & $\begin{array}{c}99.83 \\
(37.56) \\
\end{array}$ \\
\hline Conyza canadensis (L.) Cronquist & Asteraceae & Annual & Therophyte & $\begin{array}{c}69.07 \\
(11.25) \\
\end{array}$ & $\begin{array}{c}0.22 \\
(0.05) \\
\end{array}$ & $\begin{array}{l}18.46 \\
(3.60)\end{array}$ & $\begin{array}{c}0.15 \\
(0.03) \\
\end{array}$ & $\begin{array}{r}14.79 \\
(5.72) \\
\end{array}$ & $\begin{array}{c}8.19 \\
(4.99) \\
\end{array}$ & $\begin{array}{l}22.22 \\
(4.65) \\
\end{array}$ \\
\hline Equisetum arvense $\mathrm{L}$. & Equisetaceae & Perennial & Geophyte & $\begin{array}{l}30.27 \\
(9.45)\end{array}$ & $\begin{array}{c}0.38 \\
(0.13)\end{array}$ & $\begin{array}{l}22.12 \\
(7.33)\end{array}$ & $\begin{array}{c}0.17 \\
(0.03)\end{array}$ & $\begin{array}{c}3.44 \\
(3.39)\end{array}$ & $\begin{array}{c}89.07 \\
(61.27)\end{array}$ & $\begin{array}{c}2.28 \\
(0.69)\end{array}$ \\
\hline Erigeron strigosus Muhl. & Asteraceae & Annuals or biennials & Phanerophytes & $\begin{array}{c}82.53 \\
(14.52)\end{array}$ & $\begin{array}{c}0.26 \\
(0.11)\end{array}$ & $\begin{array}{l}15.11 \\
(4.77)\end{array}$ & $\begin{array}{c}0.04 \\
(0.03)\end{array}$ & $\begin{array}{l}13.87 \\
(4.20)\end{array}$ & $\begin{array}{c}15.73 \\
(12.54)\end{array}$ & $\begin{array}{c}24.68 \\
(14.81)\end{array}$ \\
\hline $\begin{array}{l}\text { Humulus japonicus Sieboid \& } \\
\text { Zucc. }\end{array}$ & Cannabaceae & Annual & Therophyte & $\begin{array}{l}88.00 \\
(9.77)\end{array}$ & $\begin{array}{c}0.07 \\
(0.03)\end{array}$ & $\begin{array}{l}18.57 \\
(7.29)\end{array}$ & $\begin{array}{c}0.04 \\
(0.01)\end{array}$ & $\begin{array}{c}4.19 \\
(2.56)\end{array}$ & $\begin{array}{l}120.52 \\
(87.10)\end{array}$ & $\begin{array}{l}108.40 \\
(49.98)\end{array}$ \\
\hline Oenothera biennis L. & Onagraceae & Biennial & Hemicryptophyte & $\begin{array}{c}81.07 \\
(17.51) \\
\end{array}$ & $\begin{array}{l}0.19 \\
(0.0) \\
\end{array}$ & $\begin{array}{l}28.55 \\
(9.31) \\
\end{array}$ & $\begin{array}{c}0.33 \\
(0.11) \\
\end{array}$ & $\begin{array}{l}18.25 \\
(8.36) \\
\end{array}$ & $\begin{array}{c}6.85 \\
(5.60) \\
\end{array}$ & $\begin{array}{c}39.24 \\
(11.87) \\
\end{array}$ \\
\hline Persicaria vulgaris Webb \& Moq. & Polygonaceae & Annual & Therophyte & $\begin{array}{c}38.60 \\
(18.02)\end{array}$ & $\begin{array}{c}0.14 \\
(0.06) \\
\end{array}$ & $\begin{array}{l}13.00 \\
(4.12)\end{array}$ & $\begin{array}{c}0.14 \\
(0.19) \\
\end{array}$ & $\begin{array}{c}7.39 \\
(4.51) \\
\end{array}$ & $\begin{array}{c}49.33 \\
(31.65) \\
\end{array}$ & $\begin{array}{c}27.98 \\
(12.99) \\
\end{array}$ \\
\hline Phragmites japonica Steud. & Poaceae & Perennial & Phanerophytes & $\begin{array}{c}77.8 \\
(25.61) \\
\end{array}$ & $\begin{array}{c}0.48 \\
(0.25) \\
\end{array}$ & $\begin{array}{c}24.25 \\
(10.43) \\
\end{array}$ & $\begin{array}{c}0.11 \\
(0.04) \\
\end{array}$ & $\begin{array}{l}13.06 \\
(4.56) \\
\end{array}$ & $\begin{array}{c}19.12 \\
(13.51) \\
\end{array}$ & $\begin{array}{c}52.11 \\
(26.88) \\
\end{array}$ \\
\hline Rorippa palustris (Leyss.) Besser & Brassicaceae & Annual & Therophyte & $\begin{array}{l}50.47 \\
(13.8)\end{array}$ & $\begin{array}{c}0.16 \\
(0.08)\end{array}$ & $\begin{array}{l}15.55 \\
(5.32)\end{array}$ & $\begin{array}{c}0.08 \\
(0.02)\end{array}$ & $\begin{array}{c}7.89 \\
(4.29)\end{array}$ & $\begin{array}{c}24.63 \\
(13.57)\end{array}$ & $\begin{array}{c}25.91 \\
(17.12) \\
\end{array}$ \\
\hline
\end{tabular}

601 Values are means with standard deviation in parentheses. 
603

\begin{tabular}{|l|r|r|}
\hline Vegetation parameters & RDA 1 (46.2\%) & RDA 2 (1.2\%) \\
\hline Vegetation Cover & $\mathbf{- 0 . 4 5 3}$ & -0.802 \\
\hline Species richness & $\mathbf{- 0 . 6 8 0}$ & -0.243 \\
\hline Root density & $\mathbf{- 0 . 9 6 0}$ & 0.278 \\
\hline Soil parameters & RDA 1 $(42.9 \%)$ & RDA 2 $(1.4 \%)$ \\
\hline Bulk density & -0.399 & -0.322 \\
\hline Water content & -0.225 & -0.691 \\
\hline Wettability & -0.332 & -0.595 \\
\hline Clay \% & $\mathbf{- 0 . 7 9 4}$ & 0.427 \\
\hline Silt \% & $\mathbf{- 0 . 8 5 7}$ & 0.295 \\
\hline Plant functional traits & RDA 1 $(49.5 \%)$ & RDA 2 $(3.9 \%)$ \\
\hline Plant height & $\mathbf{- 0 . 5 4 0}$ & 0.180 \\
\hline Root/shoot ratio & $\mathbf{- 0 . 7 9 0}$ & -0.463 \\
\hline Root length & $\mathbf{- 0 . 5 4 4}$ & 0.265 \\
\hline Root diameter & 0.225 & -0.598 \\
\hline Root horizontal width & $\mathbf{- 0 . 3 7 2}$ & -0.656 \\
\hline Specific root length & -0.087 & 0.575 \\
\hline Leaf size & 0.110 & 0.452 \\
\hline
\end{tabular}

604

605 


\section{Figure legends}

607 Fig. 1. A conceptual path model for effects of the abiotic soil characteristics (soil texture "silt \% and 608 clay\%"), vegetation characteristics (vegetation cover, species richness and root density) and PFTs (RSR = $609 \operatorname{root} /$ shoot ratio, $\mathrm{RL}=$ root length and RW = root horizontal width) on three soil stability measures (Soil 610 aggregate stability, soil penetration resistance and soil shear vane strength). Numbers on arrows indicate 611 previous studies that support the path. 1. Lane et al. (1998), 2. Denef and Six (2005), 3. Petchey and 612 Gaston (2002), 4. Pohl et al. (2009), 5. Reich et al. (2012), 6. Pérès et al. (2013) and 7. Gyssels et al. 613 (2005).

614

617 Fig. 3. The path models outputs for the effects of the soil texture "silt \% and clay\%", vegetation cover, 618 species richness, root density and PFTs "root/shoot ratio, root length and root horizontal width" with 619 accounting for the intraspecific trait variability, on three soil stability measures. (a) soil aggregate stability 620 (b) penetration resistance and (c) soil shear vane strength. Numbers on arrows are standardized path 621 coefficients. Solid arrows are positive and dashed are negative, bold arrows indicate significant 622 standardized paths $(\mathrm{P}<0.05)$; thin arrows indicate non-significant path coefficient $(\mathrm{P}>0.05)$. Percentages 623 close to the boxes indicate the variance explained by the model $\left(\mathrm{R}^{2}\right)$. The goodness-of-fit indices for the models are 0.58 for (a), 0.54 for (b) and 0.52 for (c).

625

Fig. 4. The standardized path coefficient for direct and indirect effects of PFTs "root/shoot ratio, root length and root horizontal width", root density, soil texture "silt \% and clay\%", species richness and vegetation cover on (a) soil aggregate stability, (b) soil penetration resistance and (c) soil shear strength.

Fig. 5. The path model crossloadings effect of the soil texture "silt and clay contents" and PFTs "root/shoot ratio, root length and root horizontal width" on (a) soil aggregate stability, (b) soil penetration resistance and (c) soil shear strength. 
634

635

636

637

638
Fig. 1.

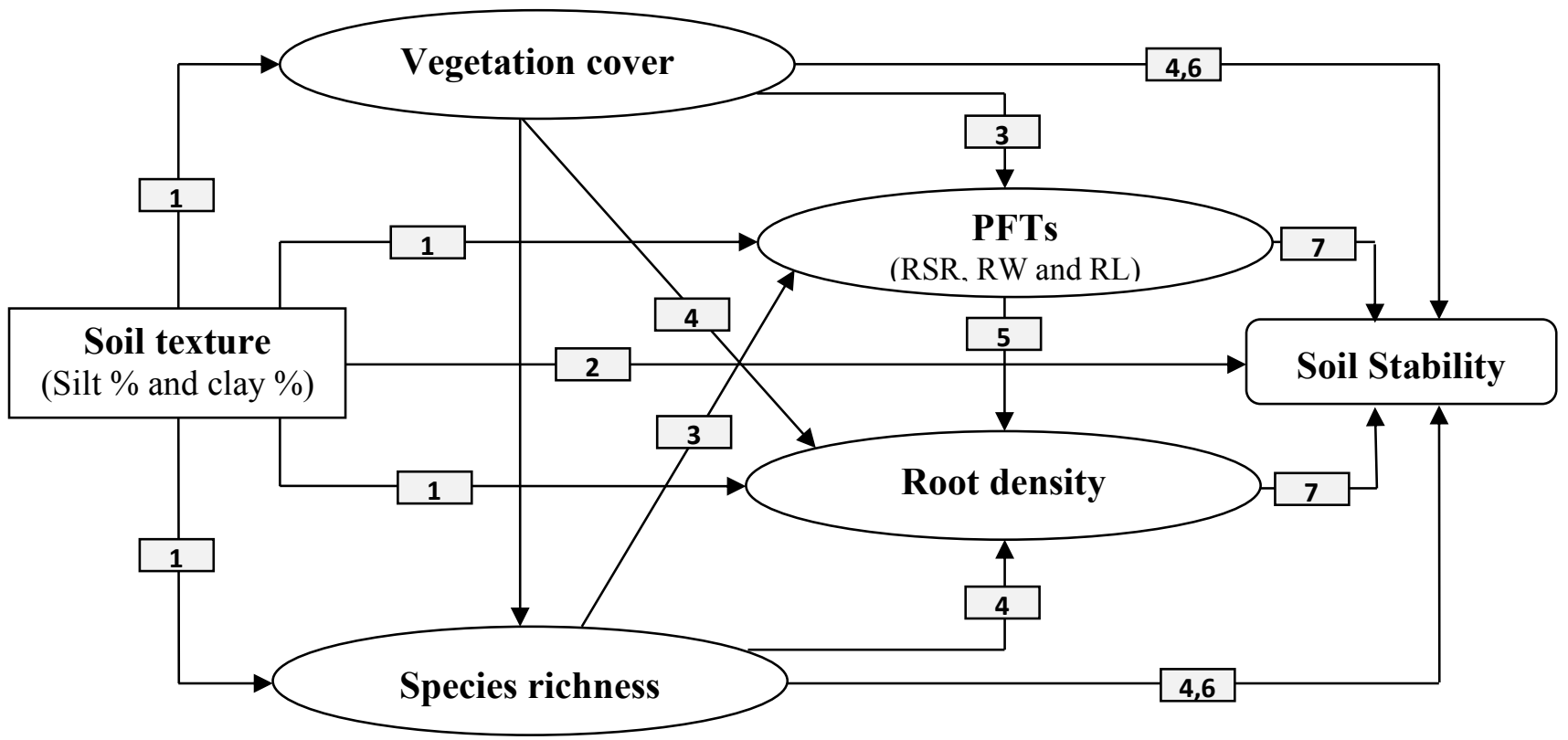


Fig. 2.

640
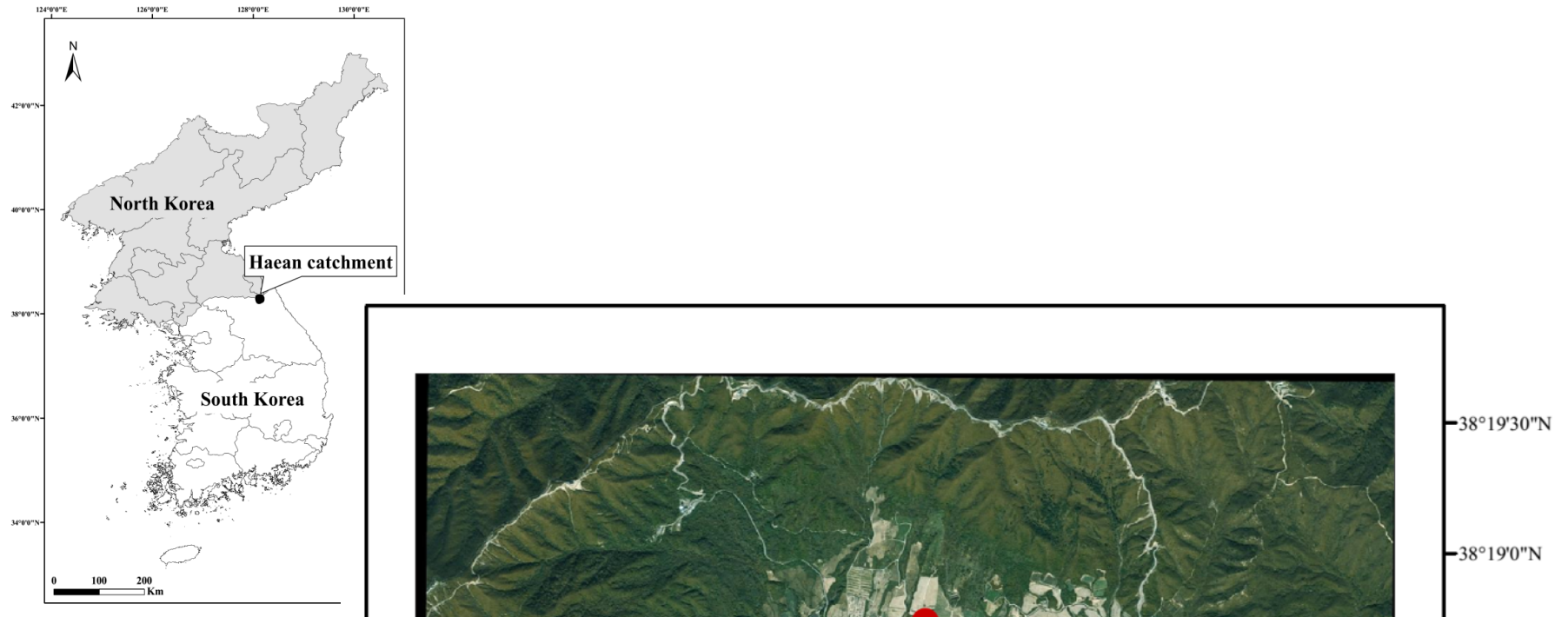

$-38^{\circ} 19^{\prime} 0^{\prime \prime} \mathrm{N}$

$38^{\circ} 18^{\prime} 30^{\prime \prime} \mathrm{N}$
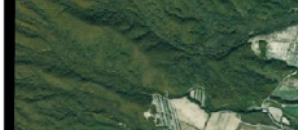

튼

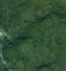

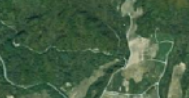

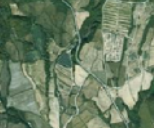
* 50
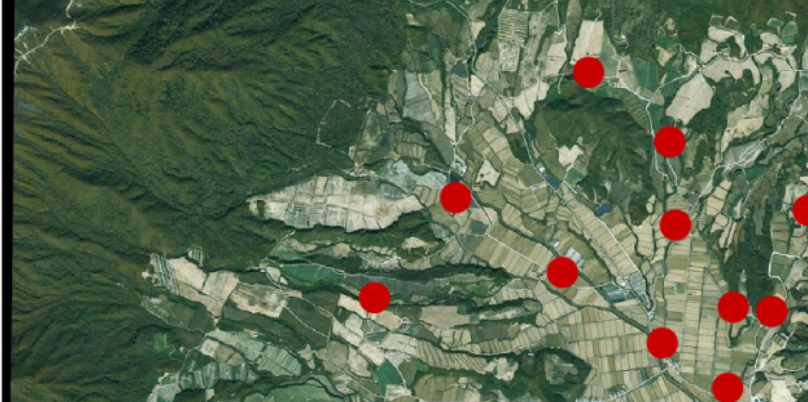

जit. $x$
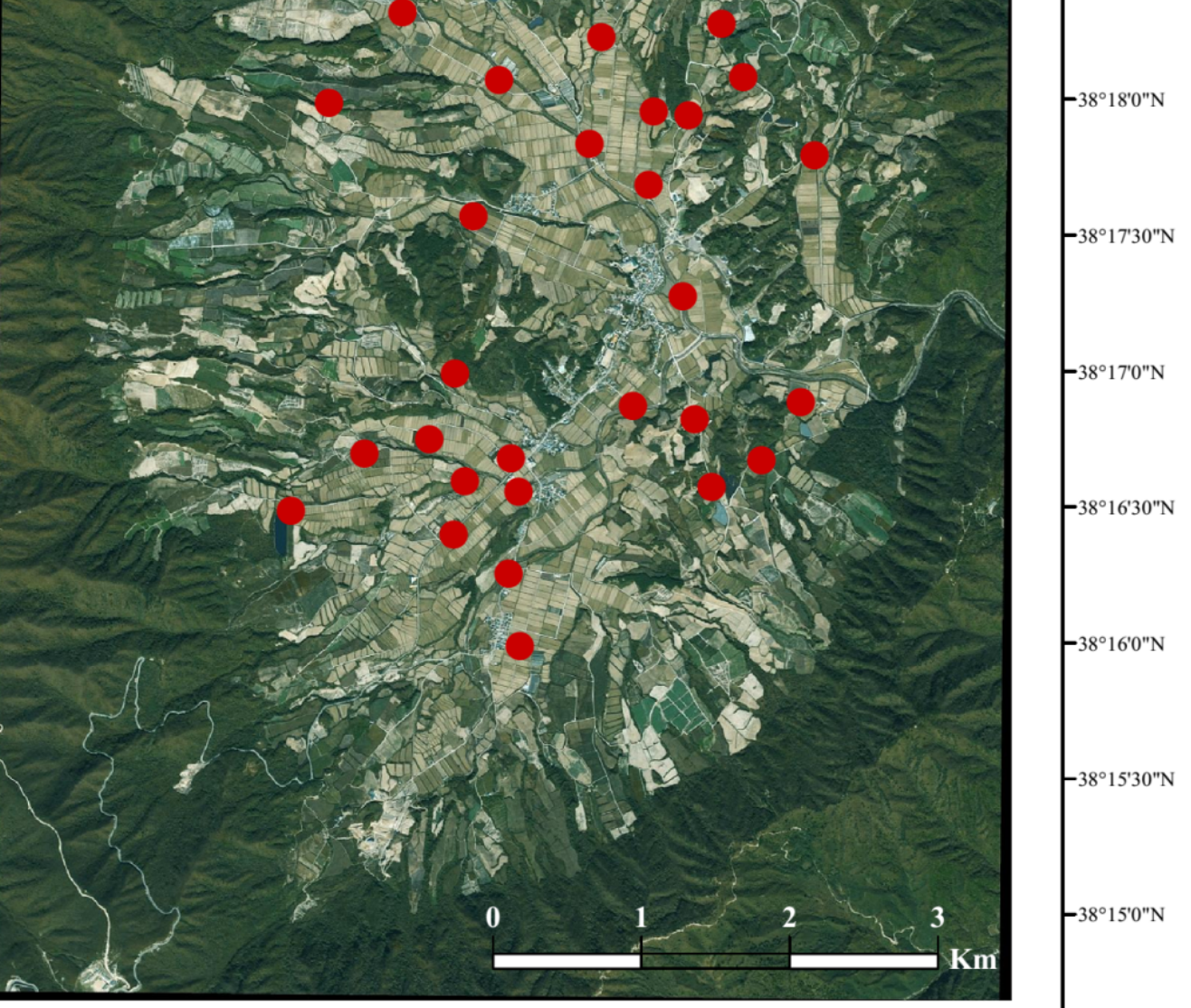

$-38^{\circ} 17^{\prime} 0^{\prime \prime} \mathrm{N}$

$-38^{\circ} 16^{\prime} 30^{\prime \prime} \mathrm{N}$ 
642

643

Fig. 3.

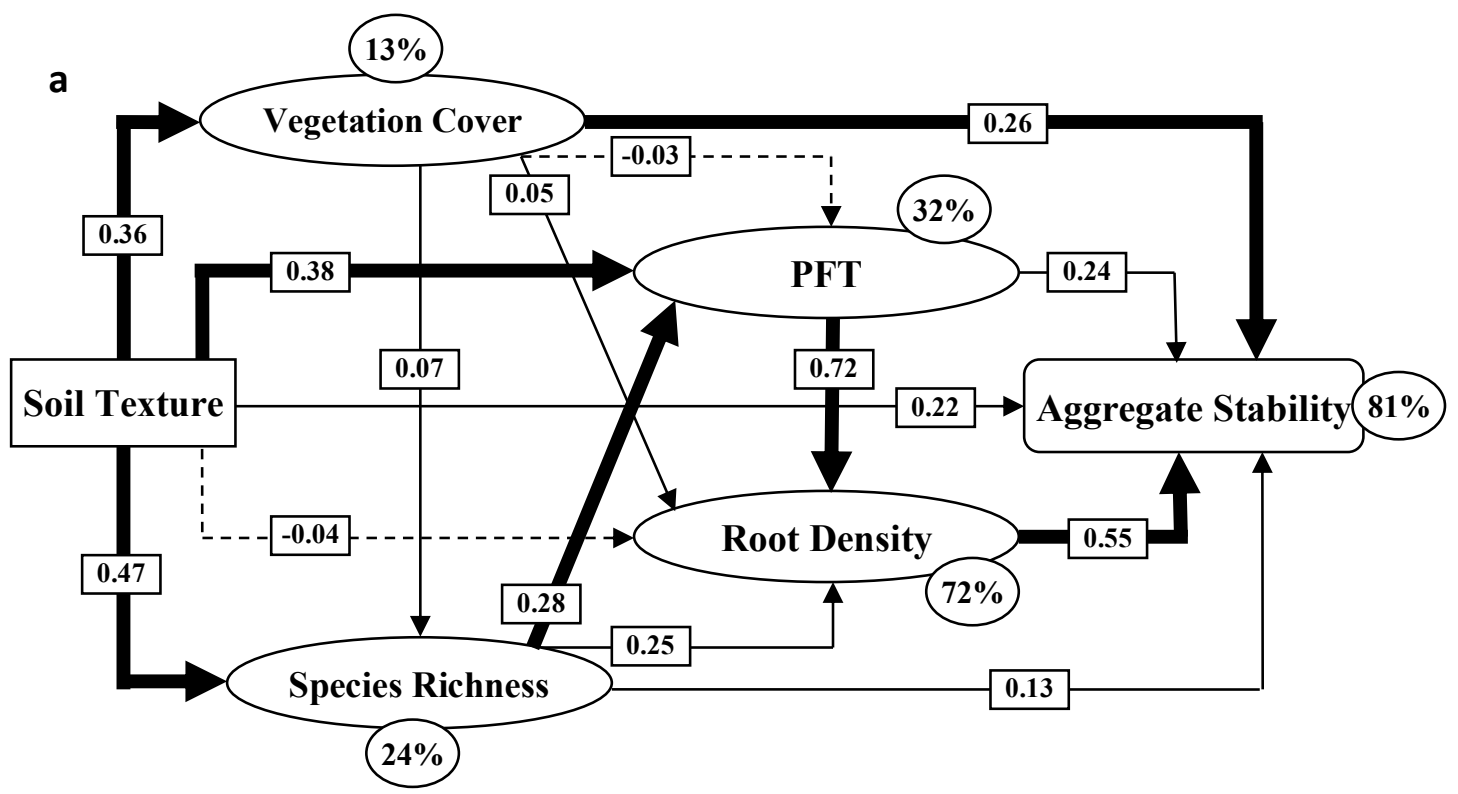


648
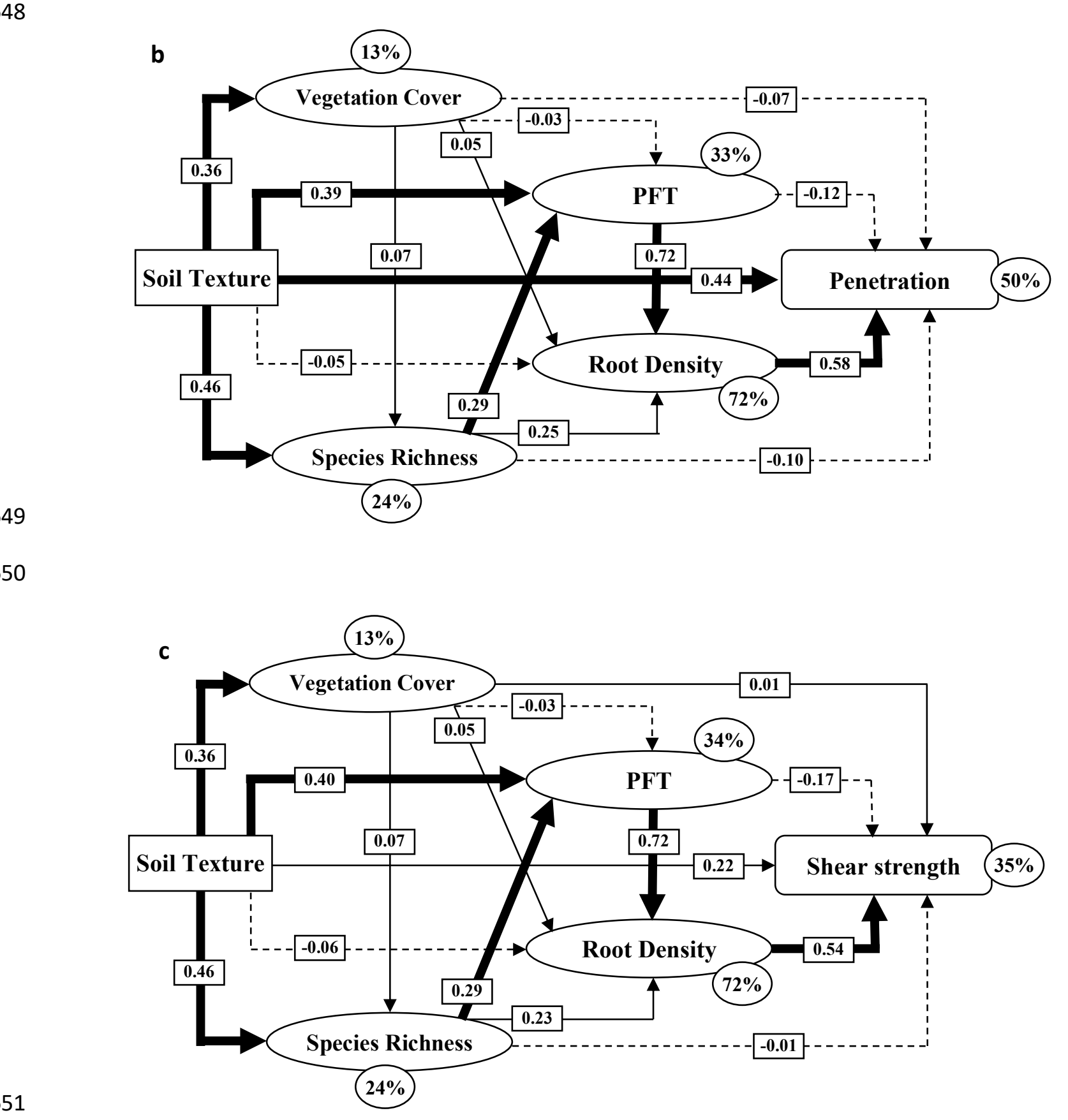

Fig. 3 (cont.).

9


Fig. 4.
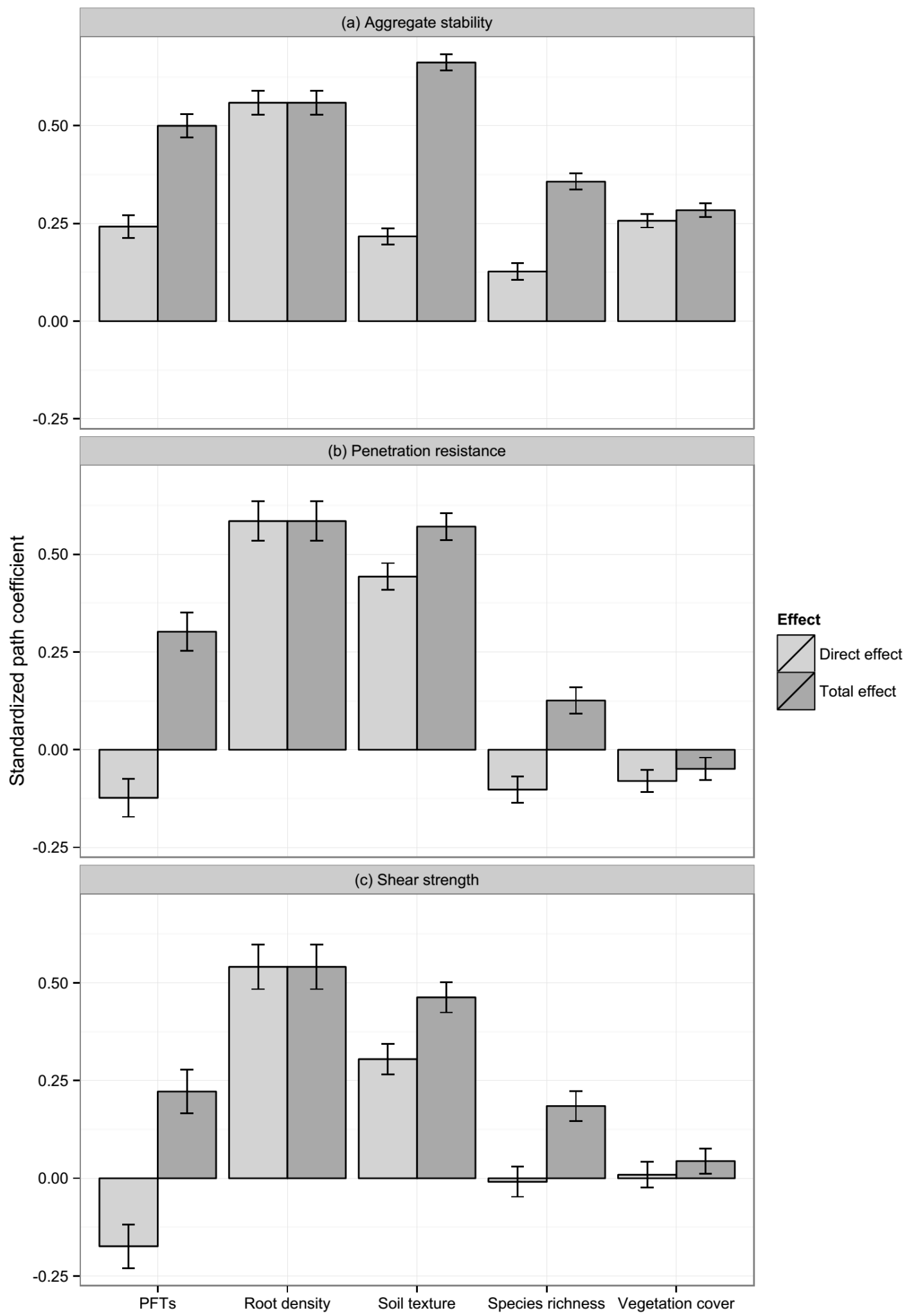
Fig. 5.
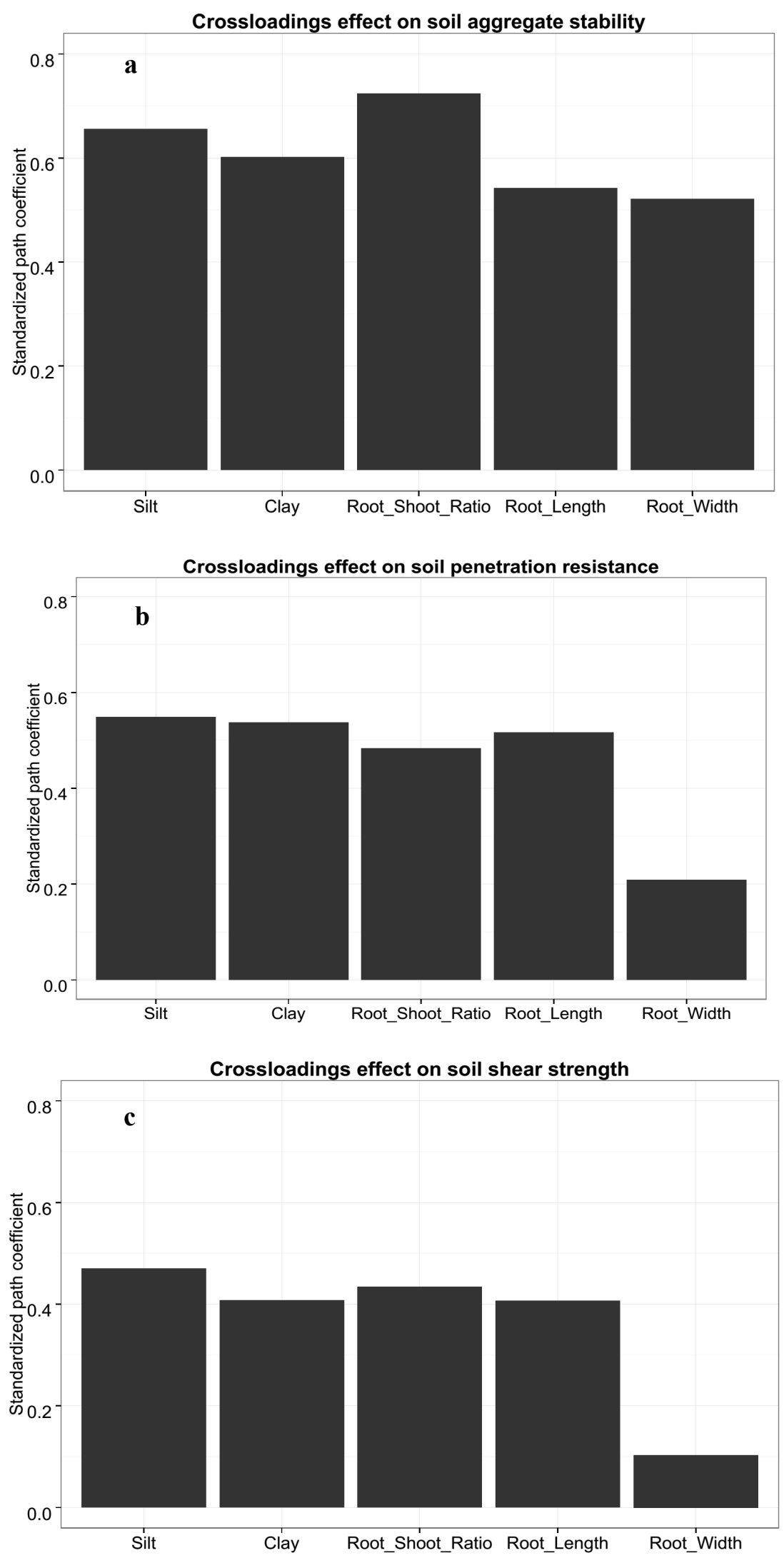